\title{
Clinical and Psychological Correlations between Job Loss and Depressive Experience
}

\author{
Ferencz Melinda ${ }^{1,2^{*}}$, Irimia Elena-Ramona², Buicu Gabriela Elena1,3, Moica Theodor ${ }^{1,2}$, Gabos Grecu \\ Cristian $^{1,2}$, Sabău Daniela Claudia',2, Gabos Grecu losif1,2 \\ 1 University of Medicine and Pharmacy, Tirgu Mures \\ 2 First Clinic of Psychiatry, Tirgu Mures \\ ${ }^{3}$ Mental Health Center, Tirgu Mures
}

\begin{abstract}
Introduction: Stressful life events have a negative effect on mental health. Job loss is an event with a psychotraumatic character. Identification of the main sources of stress faced by the individual is essential in the management of depression.

Objective: The aim of this study was to identify the main risk factors that play a role in the onset and maintenance of depression.

Material and methods: we made a prosepctive study including 68 outpatients aged over 18, recently diagnosed with Major Depressive Disorder (MDD), without psychotic features, with initiated antidepressant treatment, being in evidence of First Clinic of Psychiatry Tirgu-Mures, between 01.01.2013-31.12.2013. To assess the severity of depression and to measure the antidepressant treatment efficacy we used Hamilton Depression Scale (HAM-D17) at study onset, respectively at endpoint. The parameters followed were: HAM-D17 score, response to treatment, the mean number of hospitalizations in a year.

Results: The group included $82.35 \%$ women and $17.65 \%$ men, mostly from urban areas, aged between 35 and 68, with a HAM-D17 score between 24 and 27. The major stressful life events inventory shows that $20.58 \%$ of the patients were unemployed. The observed effects were more extensive in men.

Conclusions: How stressful life events exert their influence on mood is complex. The onset of depression often seems to coincide with a stressful event, although sometimes the event is only the revelator of an episode ready to trigger. The findings indicate the need of prevention politics for relapse of the disease, which is a disadvantage regarding the re-employment.
\end{abstract}

Keywords: depression, unemployment, stressful

Received: 09 December 2014 / Accepted: 18 July 2015

\section{Introduction}

Psychiatric disorders, like all illnesses, are caused by multiple and diverse influences - some known, many unknown. The contribution of specific 'causes' differs from patient to patient, but as a rule each of the major psychiatric disorders is characterized by a well-established set of risk factors [1].

Numerous studies highlight objectively the existing causal links between stressful life events experienced by the subject and his depression [2]. Life events, especially negative ones, lead to an increased risk of psychiatric disorder, notably depression [1]. Many studies show that the unemployed are less healthy, both physically and psychologically and self-rate their health as poorer than those who are employed. One possible explanation for the above findings is that unemployment can be a stressful life circumstance which can have deleterious effects on health. Another possible explanation is that healthy persons are less likely to lose their jobs and more likely to find new jobs once they do become unemployed. In contrast, individuals in poor health are more likely to be laid off or quit voluntarily [3].

Theoretical reasoning indicates that unemployment and health problems are intertwined in a continuously ongoing process in which deterioration of health is acceler- ated by the stress and the psychosocial and socio-economic disadvantages of unemployment, and marginalization in the labor market is accelerated by health-related selection [4].

The demographic profile of the developed world is changing. Population ageing means that many countries are facing slow growth or even contraction of the labor force. Couplet with growing numbers of old people this means that a smaller proportion of the population will be of working age and that they have to support a growing number of economically inactive individuals. This development has potentially negative consequences for standard of living [5]. Some studies found that workers with chronic diseases and depression are at higher risk of unemployment than healthy workers, but not all studies find evidence for health selection effects on employment [3]. Being female, older age, and growing number of unemployment episodes has significant effect on development of depression, while having higher education and higher income reduce the risk [6].

This study aims to highlight, through correlation analysis of the significance of stressful life events and application of research models oriented on depression risk factors, in order to prevent risky life behaviors. 


\section{Material and method}

We carried out a prospective study at First Clinic of Psychiatry from County Clinical Hospital Mures, between 01.01.2013 and 31.12.2013, which included 68 patients aged over 18 , recently diagnosed with MDD, without psychotic features, with initiated antidepressant treatment. We have followed the incidence of unemployment/problems at workplace at patients with first episode of depression, the severity of depression, the treatment and the evolution of depressed mood at this patients and the mean number of hospitalizations in a year. We used Hamilton Depression Scale with 17 items (HAM-D17) at study onset, respectively at endpoint. This scale is a multiple item questionnaire used to provide an indication of depression, and as a guide to evaluate recovery $[7,8]$. In HAM-D 17, symptoms are defined by anchor point descriptions (ranging from 3 to 5 possible responses), which increase in severity. Clinicians consider intensity and frequency of symptoms based on patient response and observations. A score of $\leq 7$ is widely thought to indicate remission [9].

Statistical analysis was performed using the Graph pad Prism. Data were labeled as nominal or quantitative variables. Nominal variables were characterized by means of frequencies. Quantitative variables were tested for normality of distribution using Kolmogorov-Smirnov test and were described by mean \pm standard deviation or median and percentiles $(25 ; 75 \%)$, whenever appropriate. The frequencies of nominal variables were compared with a chi-square test. Differences in the mean or median between groups were analyzed using the $t$ test, and ANOVAs test. The level of statistical significance was set at $\mathrm{p}<0.05$.

\section{Results}

During 2013 we had 68 new cases of MDD, first episode, without psychotic features, with initiated antidepressant treatment. The group included $56(82.35 \%)$ women and $12(17.65 \%)$ men, most of all from urban areas, namely 40 cases $(58.8 \%)$, compared with 28 cases $(41.2 \%)$ from rural areas. Only four cases $(5,9 \%)$ were under 35 years old, the rest of the patients being aged between 35 and 50 ( 25 cases), and more than 50 years old (39 cases). Regarding educational level of patients, $7.4 \%$ of the cases had only primary education, $33.8 \%$ studied in gymnasium, $38.2 \%$ high school, $16.2 \%$ vocational school and very few cases had higher education (4.4\%). Examined sample included $26(38.22 \%)$ employees, $28(41.2 \%)$ retirees and $14(20.58 \%)$ unemployed. The major stressful life events inventory shows that $20.58 \%$ of the patients were unemployed, of which one person was unemployed for less than 6 months, 10 persons between 6 months and 1 year and 3 persons over one year. From the total number of cases, 24 (35.3\%) required hospitalization during follow-up.

We did not find any statistically significant correlations between gender and age of patients $(\mathrm{p}=0.053)$, gender and study level $(\mathrm{p}=0.72)$, gender and occupation $(\mathrm{p}=0.54)$, gender and number of hospitalizations $(p=0.30)$. In- stead, we found a highly significant statistical correlation between age and occupation, with a $(\mathrm{p}=0001)$ and a statistically significant correlation in terms of occupation and education of patients $(\mathrm{p}=004)$ were unemployed for more than a year.

We did not find any significant relevance between gender for the initial Hamilton score $(\mathrm{p}=0.15)$ and Hamilton score at 6 months $(\mathrm{P}=0.93)$, between rural / urban for the initial Hamilton score $(\mathrm{p}=0.84)$ and Hamilton score at 6 months ( $\mathrm{p}=0.69$ ).

Evaluating the response to treatment of depressive illness, $25 \%$ of men and $15.4 \%$ of women responded to treatment. $6.2 \%$ of men and $17.3 \%$ of women went into remission after 6 months of treatment (Figure1).

At those from urban areas remission was lower $(7.1 \%)$ than those who were from rural areas (20\%).

Between age groups and baseline Hamilton Rating Scale for Depression, using ANOVAs test and Bonferonni's Multiple Comparison Test we found significant relevance between age groups under 35 and over 35 years $(p=0.022)$ (Figure 2) and after 6 months of treatment, using ANOVA + Bonferroni test ( $p=0.3755)$ was not found significant relevance between age groups.

We found a non-significant relevance between baseline Hamilton score of unemployees and employees; employees and pensioners, using ANOVA test $(\mathrm{p}=0.052)$ (Figure 3.),

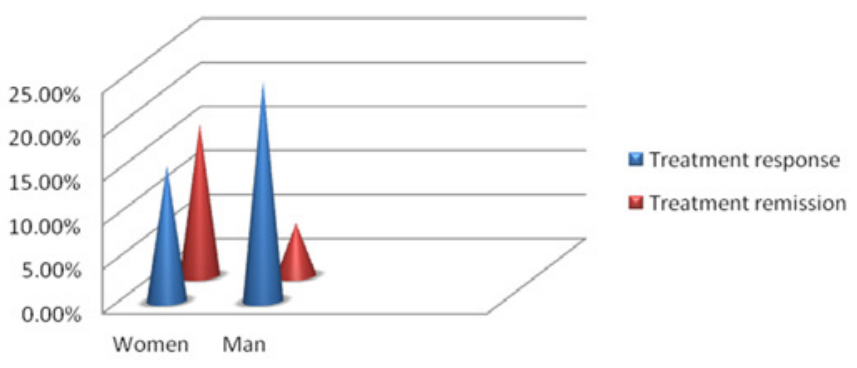

Fig.1 Response to treatment after 6 months

\section{p-0.02}

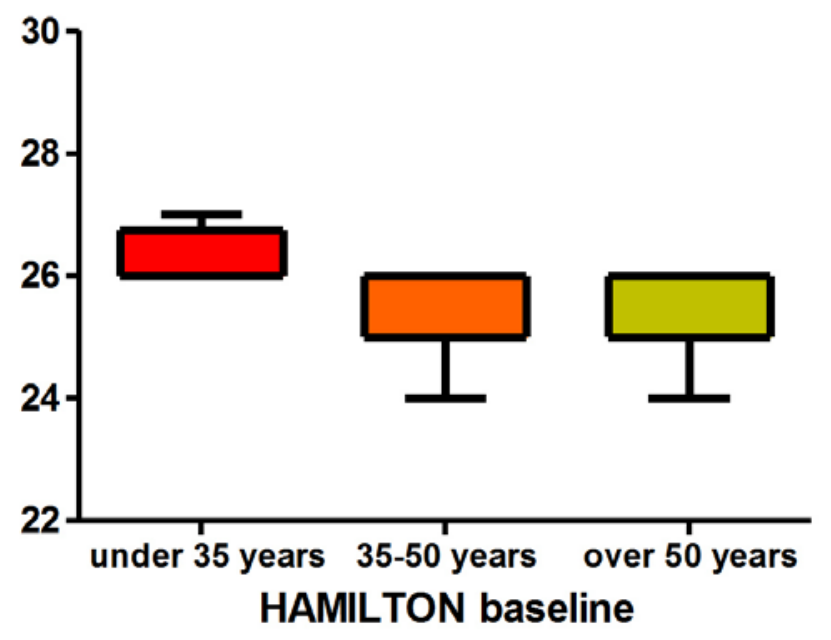

Fig.2 Baseline Hamilton score between age groups 
although between unemployed and pensioners baseline Hamilton score we found significant correlation $(\mathrm{p}=0.002)$ using Bonferroni's Multiple Comparison Test . No statistically significant difference was found between the categories of occupation and Hamilton score at 6 months (ANOVA test, $\mathrm{p}=0.8635$ ).From the study lot, $33.45 \%$ of the unemployed, $27.2 \%$ of the employees and $35.7 \%$ of the pensioners went into remission after 6 months of treatment.

\section{Discussions}

The prevalence of depressive symptoms may be as high as $30 \%$ in the general population, with women being twice as likely to be affected as men. This gender difference has been found consistently in several epidemiologic studies [12].

Our study included patients recently diagnosed with Major Depressive Disorder, first episode, without psychotic features, the majority were women and more than half were from urban areas.

According to the results and data from literature, the female gender, older age represent a risk for the occurrence of depression.

A very small percentage of the cases examined in our study had higher education, so as to higher education should reduce the risk of depression. As data from literature shows, higher education and income reduce the risk of depression [10].

$2 / 5$ of the cases were retired for various medical reasons, subsequently presenting affective disorders, $2 / 5$ of the cases were employees, but there were various reasons (trauma, stressful life events, marriage, financial troubles, etc.) in triggering of depression and 1/5 of the cases were unemployed. Several researchers have conducted metaanalysis concluding that job loss is associated with a deterioration of mental health, finding a job is associated to its improvement $[11,12,15]$.

On Hamilton Rating Scale, treatment response means

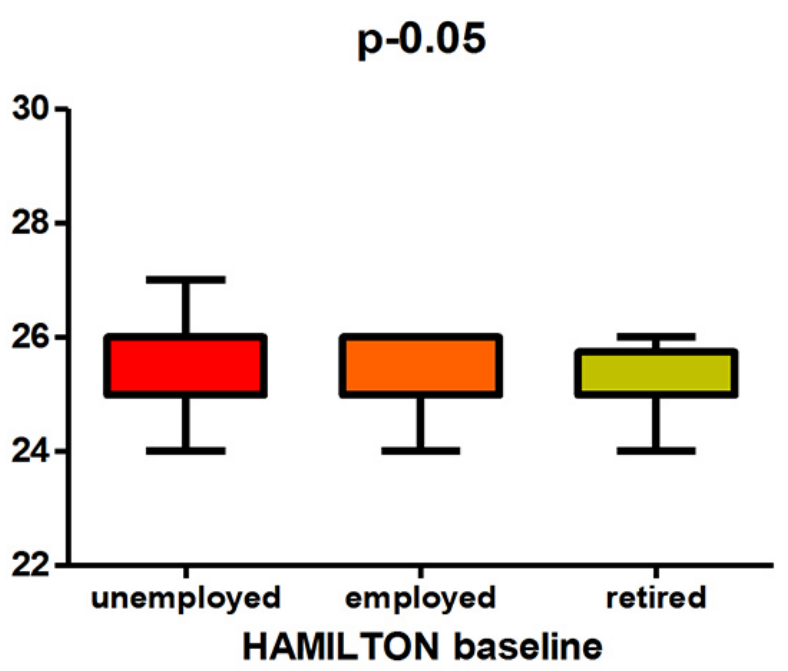

Fig.3. Hamilton baseline score between categories of occupation that the scores is decreased by $50 \%$ and remission is when the score decrease below 7 . Analyzing the remission and response to treatment between genders, we found that a smaller percentage of men versus women went into remission, but the number of men who responded to treatment after 6 months was greater.

We observed a significantly higher remission rate in patients who came from rural area ( $\mathrm{p}-001)$, possibly due to social stability and a better integration of residents.

One third of patients, who followed pharmacological treatment in each group, went into full remission after 6 months of treatment. The goal of treatment of major depression should be full remission. Many patients, however, fail to achieve or maintain symptom-free status. Residual depressive symptoms are common, even where there has been a robust response to antidepressant therapy. In clinical studies, approximately one-third of patients achieve a full remission, one-third experience a response and onethird are nonresponders $[13,14]$.

\section{Conclusions}

How stressful life events exert their influence on mood is a complex issue. The onset of depression often seems to coincide with a stressful event, although sometimes the event is only the revelator of an episode ready to trigger.

The female gender, older age represent a risk for the occurrence of depression. The observed effects are larger in men and persons unemployed for a long time.

Therefore it is necessary to acquire new skills and increase individual resilience, through intervention programs. The focus should be on neutralizing negative thoughts, on increasing self-esteem, the use of coping strategies based on problem solving to recommit, use of relaxation methods to reduce anxiety, use of coping strategies focused on emotion for preventing depression.

\section{Acknowledgement}

This paper was published under the frame of European Social Found, Human Resources Development Operational Programme 2007-2013, project no. POSDRU/159/1.5/S/ 136893.

\section{References:}

1. Gautam Gulati, Mary-Ellen Lynall, Kate Saunders: Lecture notes. Psychiatry - Eleventh edition. 2014, Ed. Wiley - Blackwell, UK, pag. 55-56.

2. Gh. Grecu, et al.: Corelatii intre evenimentele de viata stresante si tulburarile depressive, Casa de Editura Mures, 2003, Tg Mures, pag. 51-67.

3. X. Wang, J. Guo, X. Zhang, Z. Qu, D. Tian, S. Ma : The effects of depression and chronic diseases on the work outcomes of employees: a prospective study in Northwest China. Public Health. 2014; 128:734742.

4. P. Virtanen, U. Janlert, A. Hammarstro: Health status and health behaviour as predictors of the occurrence of unemployment and prolonged unemployment. Public Health. 2013;127:46-52

5. Madelene Nordlund, Tom Stehlik, Mattias Strandh: Investment in second chance education for adults and income development in Sweden, Journal of Education and Work. 2013;26:5:514-538.

6. Mindaugas Stankunas, Ramune Kalediene, Skirmante Starkuviene and Violeta Kapustinskiene: Duration of unemployment and depression: a 
cross-sectional survey in Lithuania. BMC Public Health. 2006;6:174.

7. Hamilton M.: A rating scale for depression. J Neurol Neurosurg Psychiatry 1960;23:56-62.

8. Hedlund JL, Viewig BW : The Hamilton rating scale for depression: a comprehensive review. Journal of Operational Psychiatry. 1979;10:149165.

9. Dr. Jeffrey S. Gonzalez, Erica Shreck, Abigail Batchelder: "Hamilton Rating Scale for Depression (HAM-D)", Encyclopedia of Behavioral Medicine, Ed. Springer, New York 2013, pag. 887-888

10. Ionescu S, Bouteyre E: Tratat de rezilienta asistata, Editura 3,2013, pag:445-462
11. Paul K I and Moser K, Unenployment impairs mental health: Metaanalyses. Journal of Vocational Behaviour. 2009;74:264-282.

12. D. Semple, R. Smyth, Oxford Handbook of Psychiatry, Second Ed. Oxford university Press Inc, New York, 2009, Pag. 224.

13. Tranter R1, O'Donovan C, Chandarana P, Kennedy S: Prevalence and outcome of partial remission in depression. $J$ Psychiatry Neurosci. 2002;27:241-247.

14. Emergency psychiatry / [edited by] Arjun Chanmugam, Patrick Triplett, Gabor Kelen. Ed. Cambridge University Press, New York, 2013.

15. Psychology and the Challenges of Life: Adjustment and Growth 12th edition, Jeffrey S. Nevid, Spencer A. Rathus, Ed. Wiley, 2013, USA. 